\title{
EL PAPEL DEL ESTADO EN LA INDUSTRIALIZACION DE TAIWAN, COREA DEL SUR Y MEXICO: un análisis comparativo
}

José Martínez Vilchis Facultad de Ciencias Políticas y AdministraciónPública, UAEM

\section{INTRODUCCIÓN}

Este trabajo expone algunos de los temas fundamentales que explican los modelos seguidos por los Tigres Asiáticos y por Latinoamérica. Tomaremos específicamente a tres países representativos de esas regiones para comparar como los modelos seguidos por los gobiernos de MÉXICO, TAIWAN y COREA DEL SUR EN LAS ẢREAS ECONÓMICA, POLÍTICA Y EDUCATIVA tuvieron una orientación y resultados distintos en cada nación.

Decisiones estratégicas de mediano y largo plazo ejecutadas de 1950 en adelante, contribuyeron a lograr un gran éxito económico para los dos países asiáticos. En tanto que en México, las decisiones adoptadas a partir de 1940, desembocaron en una aguda crisis durante los 80 s y en expectativas poco alentadoras para mediados de los 90s.

Después de estudiar sus respectivos procesos de industrialización, concluimos que la acción del Estado en las tres esferas mencionadas fue determinante para conformar el tipo de desarrollo económico-social que hoy poseen los países bajo estudio.

En relación a las decisiones ECONÓMICAS, trataremos seis temas:

1.- SUSTITUCIÓN DE IMPORTACIONES VS. MODELOS DE "ORIENTACIÓN HACIA AFUERA"

2.- CRECIMIENTO ECONÓMICO E INDICADORES SOCIALES

3. - MEDIDAS FINANCIERAS

4.- PROTECCIONISMO

5.- CONTROL DE LA INVERSIÓN EXTRANJERA

6.- EL PAPEL DE LA AGRICULTURA 
En relación a los aspectos POLÍTICOS, consideraremos el papel de Norteamérica en el proceso de desarrollo de los tres países y revisaremos los rasgos autoritarios y el tipo de democracia que caracterizó a sus sistemas políticos, considerándolos como dos aspectos fundamentales los cuales nos permitieron conocer el marco político bajo el cual se impulsaron sus proyectos económicos.

Finalmente, explicaremos las políticas adoptadas en el terreno EDUCATIVO Y TECNOLÓGICO ya que son claves para entender porque en el largo plazo, Taiwán y Corea del Sur alcanzaron un desarrollo sustentable. Por su parte, México no creo una sólida base de científicos y profesionales para dar viabilidad a un proyecto de desarrollo tecnológico capaz de dar competitividad a su economía en algún área de punta. Por ello, tuvo que depender de la tecnología externa y de mano de obra poco calificada, creando una dependencia asfixiante del exterior.

\section{A)-EN RELACIÓN A LA ECONOMÍA. 1.- SUSTITUCIÓN DE IMPORTACIONES VS. ORIENTACIÓN HACIA FUERA.}

El desarrollo de Taiwán y de Corea del Sur atravesó por varias etapas en su estrategia de industrialización. A diferencia del caso mexicano, los gobiernos de Taiwán y Corea del Sur no siguieron el modelo de sustitución de importaciones por más de 20 años. En términos generales podemos decir que este modelo prevaleció de 1950 a 1970 aproximadan lente, este periodo sentó las bases para después pasar hacia una agresiva política de "orientación hacia afuera”, con el subsecuente éxito en las exportaciones y en su balanza comercial. (Wade: 1990: 85).

México, por su parte, siguió la estrategia de sustitución de importaciones por un período de 30 años, 1940 a 1970 pero después de ello el Estado no tomó la misma decisión que los países mencionados, quizá por presiones para distribuir el ingreso, por necesidad de legitimación política, por la influencia de las ideas de la CEPAL, por miopía económica o por todo ello en conjunto..

Es así, que a partir de 1970 se pone en marcha el llamado "desarrollo compartido" que lejos de orientar la economía hacia la exportación prefirió intentar una política de rápida expansión del Estado propietario, ampliación del mercado interno y redistribución del ingreso. Medidas todas ellas que demostraron su poca credibilidad para las instituciones financieras internacionales como el 
Banco Mundial quienes lanzaron como alternativa el modelo de "ajuste estructural”, cuya aplicación ha resultado inexorable tarde o temprano en gran cantidad de países incluidos los del exbloque socialista.

Cabe señalar que hasta 1993, 62 países, principalmente en África, América Latina y Asia del Sur, han tomado préstamos bajo el esquema de ajuste estructural en respuesta a crisis diversas y bajo la presión de organismos financieros internacionales (Moser: 1993: s/pag.)

\section{TENDENCIAS EN EL CASO MEXICANO.}

Dos argumentos fueron básicos para sostener la sustitución de importaciones en México y América Latina:

- La demanda para exportar el tipo de producto de estos países no se incrementaría a un ritmo tal, que fuera suficiente para sostener altos promedios de crecimiento económico.

- El proteccionismo (opuesto a las ideas de un mercado externo competitivo), fue practicado ampliamente principalmente en las industrias nacientes en la presencia de economías de escala.

En las primeras etapas de la sustitución de importaciones, el país crece porque la demanda interna reemplaza las importaciones, pero cuando el mercado interno se satura, la producción se detiene obviamente. En este momento las exportaciones podrían aliviar el problema, sin embargo los bienes producidos en México bajo el proteccionismo del Estado, no tienen la calidad adecuada y no son competitivos en el exterior. La otra solución, que era la de pasar a la etapa de producción de bienes de capital (por ejemplo, maquinaria y equipo), fue tímida o nulamente ejecutada en los países de Latinoamérica.

\section{TENDENCIAS EN EL CASO DE TAIWÁN Y COREA DEL SUR}

Los dos más importantes elementos de la estrategia "hacia afuera" fueron: -MODERACIÓN

-NEUTRALIDAD

Por MODERACIÓN se entiende, que se da trato preferencial a ciertas actividades de manufactura, esta debería ser aplicada en escala moderada y por un periodo limitado. En ambos países, los programas de sustitución no fueron desmantelados totalmente al adoptar el modelo "hacia afuera". Pero aunque el proteccionismo se continúo dando en empresas seleccionadas, los niveles de protección tendieron a ser bajos. Aún más, las industrias protegidas 
tuvieron un plazo perentorio para volverse competitivas. En adición, los promedios de las tarifas de exportación fueron más bajos en estos países que en México. (Naya: 1990: pag.308).

Por NEUTRALIDAD, se entiende que los productos fueron sometidos a igual tratamiento, ya sea que ellos hayan decidido exportar sus productos o producir el mercado interno. Estos países evitaron las políticas discriminatorias en contra de las exportaciones. Por ejemplo las licencias de importación fueron reducidas para facilitar la compra de materiales y equipo necesarios para producir.

Otras medidas adicionales fueron tomadas por muchos de los llamados NICs, es decir países mas recientemente industrializados (Singapur, Corea del Sur, Taiwán y Hong Kong) o los países Asiáticos del Sureste, que empiezan a sostener un constante progreso económico (Indonesia, Malasia, Filipinas, y Tailandia), tales medidas fueron las de devaluar su moneda para estimular las exportaciones, y ofrecer toda clase de incentivos a las mismas.

En el caso de Corea del Sur, destaca su pragmatismo para manejar la economía, pues al mismo tiempo que aplicó altos niveles de proteccionismo creo más subsidios para las industrias exportadoras. Es decir, en correspondencia a un proteccionismo aplicado a la industria de manufactura ligera, el gobierno promovió el desarrollo de la industria pesada y de la química, orientadas a la exportación fundamentalmente a partir de la década de los setenta, alternativa esta, por la que no quisieron optar los encargados de la política eco-nómica en México.

\section{LOS ELEMENTOS COMUNES EN EL AVANCE ECONÓMICO DE LOS NICs SON:}

I. Una consistente política económica basada en la flexibilidad apoyando la sustitución de importaciones pero cambiando rápidamente hacia el modelo exportador;

II. II. Proteccionismo en algunas áreas de la industria y al mismo tiempo impulso a la creación de industrias de punta y a la exportación de sus productos;

III. Altos niveles de consenso hacia las medidas del gobierno, de parte de los industriales y los trabajadores. Es decir, políticas comerciales, financieras industriales y laborales trabajando en armonía.

IV. Creencia en el mercado de exportación aunque se encuentre en apariencia saturado o estancado. Si los países se vuelven mas competitivos pueden 
cambiar la composición del control de este mercado. Por ejemplo, los NICs fueron capaces de desbancar a Japón como principal abastecedor de equipo eléctrico doméstico en el mercado norteamericano

V. Producción de manufacturas que requieren un uso intensivo de mano de obra en un primer momento, para después asaltar el área de exportación de bienes de alta tecnología que requieren mano de obra calificada.

\section{PRINCIPAL DIFERENCIA CON AMÉRICA LATINA}

Pocos países en la región se especializaron en manufacturas debido a su predominancia de materias primas. En los 80s, México junto con varios países incluyendo Argentina y Colombia, empezaron a perder la ventaja comparativa que tenían en la producción de bienes que requieren mano de obra intensiva. Lo más preocupante es que las exportaciones de bienes de tecnología intensiva o de capital humano no tomaron su lugar como en el caso de los NICs. (Naya: 1990: 311)

Brasil es el país que ha seguido el mas consistente modelo "hacia afuera" entre los países de la región siguiendo un patrón similar al de los países del sureste o con una continua especialización en la producción de bienes de mano de obra intensiva no calificada $y$ un pequeño incremento en exportaciones de tecnología intensiva. Esto lo coloca según las proyectos y escenarios que ya se trazan, como el país de :a Latina que mas ganancias tendrá seguido por México en el marco de la ronda Uruguay del GATT, próximo a ser sustituido por la Organización Mundial Comercio (OMC)

\section{2.- CRECIMIENTO ECONÓMICO E INDICADORES SOCIALES 2.1 TAIWAN Y COREA DEL SUR HAN SOSTENIDO SU CRECI- MIENTO A DIFERENCIA DE MÉXICO}

Los países asiáticos han sostenido sus altas tasas de crecimiento económico no solo entre 1950 y 1970 sino también durante la década de los 80s a diferencia de México. El promedio para los NICs se ubicó en el 7.5\% en tanto que para México los 80 s se han considerado como la década pérdida dado que tuvimos cifras negativas en varios de los años y crecimientos positivos muy raquíticos en otros. El promedio anual de crecimiento del PIB, entre 1982 y 1988 fue del 0.9\% muy abajo del porcentaje de crecimiento de la población. 


\subsection{DISTRIBUCIÓN DEL INGRESO}

Como resultado de la disparidad en el crecimiento de estos países, ha habido un cambio en los niveles del ingreso per cápita verdaderamente dramático como podemos observar en el cuadro siguiente (World Bank: 1992: 218):

\begin{tabular}{lrr}
\hline PIB PER CÁPITA (DOLARES) & $1960(1)$ & 1990 \\
& & \\
\hline Corea del Sur & 295 & 5,400 \\
& & \\
\hline Taiwán & 446 & $5,922^{*}$ \\
\hline México & 1,266 & 2,490 \\
\hline${ }^{*} 1988$ & &
\end{tabular}

(1) Datos de1 libro estadísticas financieras internacionales 1987 del FMI

Los dos países asiáticos, han incrementado su PIB per cápita en proporciones asombrosas en un período de 30 años. En el caso de Corea en alrededor del $1900 \%$ y en el caso de Taiwán en alrededor del 1300\%. En tanto que México solamente lo hizo en alrededor $100 \%$. Esto se entiende si consideramos que la de los 80 s ha sido de resultados muy diferentes para los tres países en cuanto a crecimiento del PIB, como lo señalamos líneas arriba.

\section{3.-MEDIDAS FINANCIERAS 3.1- INFLACIÓN}

La gran diferencia en relación a las medidas financieras tomadas en los dos NICs, en comparación con México, se aprecia en el indicador de la inflación. Entre 1960 y 1969 México aun gozaba de los beneficios del modelo de sustitución de importaciones en medida que Corea y Taiwán y esto se reflejaba en el promedio inflacionario para el período, que se situaba en los siguientes niveles:

Taiwan

Corea del Sur México
$4.9 \%$

$13.4 \%$

$2.7 \%$

Un dramático vuelco ocurrió durante los setenta cuando el aumento de los precios del petróleo empujó la inflación hacia arriba. Ante ello, los asiáticos 
rápidamente controlaron los precios y optaron por reducir el crecimiento para no permitir la inflación. El gobierno Coreano redujo el gasto público e incrementó los préstamos disponibles para el sector privado.

$\mathrm{Al}$ mismo tiempo, los intereses reales se mantuvieron positivos y los influjos de capital externo se limitaron para asegurar la deseada estabilización de los niveles de precios domésticos sin una sobrevaluación excesiva del tipo de cambio. Esto permitió a Corea pasar a una baja inflación con gran éxito.

En México por el contrario, al iniciar los setenta el gobierno lanzó una serie de medidas económicas entre las que se encontraban: la expansión del gasto público, la creación de empresas paraestatales y la ampliación del mercado interno. Todo ello llevo a incremento notorios de la inflación que entre 1973 y 1976 alcanzó el 18.8\%. El endeudamiento externo se eligió para financiar en parte este programa y por consecuencia la deuda aumentó de 3 mil a 16 mil millones de dólares entre 1970 y 1976.

Las consecuencias no se hicieron esperar y en 1976, México se vio obligado a devaluar en alrededor de $80 \%$ su moneda que había permanecido estable por 22 años.

Como resultado de la diferencia en las medidas tomadas por Taiwan y Corea en contraste con México, los promedios de inflación entre 1980 y1988 se ubicaron así:

$\begin{array}{lc}\text { Taiwan } & 4.7 \% \\ \text { Corea del Sur } & 8.7 \% \\ \text { México } & 74.5 \%\end{array}$

\subsection{ALTOS PROMEDIOS DE AHORROS E INVERSIÓN}

El ahorro interno permitió a los países asiáticos financiar mucha de su inversión doméstica y fue incrementado paulatinamente entre 1960 y 1980. Si observamos la evolución de estos niveles de ahorro nos percataremos que Taiwan y Corea del Sur, lo incrementaron a un ritmo más notorio que el de México. Veamos:

Taiwan incrementó su promedio de ahorro interno bruto como porcentaje del PIB, de $19.8 \%$ en 1960 a $34.1 \%$ en 1980

Corea del Sur por su parte elevó el mismo indicador de $11.5 \%$ al 31.9\%.

México a su vez, tenía un porcentaje de $18.4 \%$ en 1960 (mas alto que el de Corea), pero solo lo aumentó al 25.6\% en 1980 para quedar en el nivel mas bajo de los tres países comparados. 
La gran ventaja de apoyar el crecimiento en el ahorro interno, es que se evita la utilización de grandes préstamos. Taiwan utilizo este ahorro como fuente principal de ingreso, y aunque Corea lo hizo en menor grado, decidió levantar políticas para transferir recursos de un sector de la economía hacia otro. Por ejemplo, entre 1977 y 1979, 4/5 partes del total de la inversión en manufacturas se trasladó hacia las industrias pesada y química. (Wade, 1990:321)

\subsection{EJEMPLOS DE COMO LOS ASIATICOS HAN REGULADO EL MERCADO CONTRAVINIENDO LA ORTODOXIA LIBERAL}

Los NICs han utilizado el poder del Estado en ciertas etapas de su desarrollo, incluso regulando la producción. Para algunos autores, los asiáticos han estado "GOBERNANDO EL MERCADO". El término alude a un uso flexible del poder del Estado para inclusive diseñar y ejecutar medidas económicas a veces aparentemente opuestas a lo que mandan los cánones liberales pero solo de manera temporal para Introducir un sesgo particular a la etapa de crecimiento económico puesta en marcha, pero siempre dentro del desarrollo capitalista. Quizás asistimos a la ejecución de una de las combinaciones mas exitosas entre Keynesianismo y liberalismo que la humanidad haya conocido jamás.

\section{ASIGNACIÓN DE RECURSOS}

Hay un ejemplo muy ilustrativo que se refiere al modo en que los recursos financieros son asignados porque la experiencia de Taiwán y Corea ha demostrado que esto tiene un impacto en los patrones de desarrollo.

El ejemplo de Taiwán es muy importante porque en algunas etapas de su desarrollo, aplicó medidas que se considerarían poco ortodoxas o hasta audaces, por ejemplo, se argumenta que los mercados financieros regulados tienden a asignar los recursos de manera equivocada porque las decisiones están en manos del gobierno y no en manos del mercado. Sin embargo, durante los 50s, Taiwán incrementó las tasas de interés, cuando la sabiduría popular recomendaba mantener las tasas bajas para estimular la inversión y el crecimiento. Las altas tasas en Taiwan estimularon el ahorro y el gobierno reguló la asignación de capital porque tenía la intención de dar acceso al capital a las industrias medianas y pequeñas. De ahí, que la dominación de la economía por grandes firmas, no se dio en Taiwan como en otros países.

Corea del Sur por su parte, optó por subsidiar crédito a industrias seleccionadas. El crédito para las pequeñas y medianas industrias fue restringido optan- do por un crecimiento basado en los grandes consorcios. 
Es un hecho que la represión financiera fue mayor en los países asiáticos que en los latinoamericanos pero lo que hizo la diferencia fue la asignación de recursos hacia las industrias mas eficientes. Tan es así, que las altas tasas de crecimiento en los países asiáticos se han sostenido por más tiempo y sobre bases más sólidas que las de los países latinoamericanos.

Una de las conclusiones mas importantes que se manejan para explicar el éxito asiático es que la intervención del gobierno puede bajo ciertas circunstancias, ser efectiva y eficiente si existen medidas inteligentes y ausentes de interferencias políticas y de corrupción que distorsionen los programas económicos

\section{4.- PROTECCIONISMO}

De acuerdo a los cánones del liberalismo económico, el proteccionismo es una medida que no debe ser aplicada a porque interfiere con la libertad que las fuerzas del mercado necesitan. Sin embargo en la realidad, los grandes apologistas del liberalismo como Norteamérica o Gran Bretaña usan medidas proteccionistas cuando así conviene a sus economías y castigan a los demás países cuando a su juicio se han excedido en tales medidas.

Lo cierto es que el ejemplo de Taiwan y Corea nuevamente nos ilustra sobre la manera diferente en que ellos aplicaron su política proteccionista y cual fue la diferencia con el caso de México.

El proteccionismo de los dos países asiáticos, se ha expresado a través de diversas medidas como: altas tarifas arancelarias, regular la procedencia de los productos de importación e incluso señalar que industrias podían importar y cuales no, el control del tipo de cambio, limitantes para la inversión extranjera directa, etc. La clave pareció estar en ejercer un proteccionismo selectivo en las industrias competitivas.

En el caso de México, durante el período de sustitución de importaciones, se apreció un proteccionismo casi indiscriminado, que condujo hacia industrias ineficientes y creo rigideces para adaptar sus políticas y tomar ventaja de las nuevas condiciones internacionales en su momento.

La siguiente cita de Wade, ilustra como el gobierno mexicano no pretendió mediante el proteccionismo crear una industria automotriz nacional capaz de crear su propia tecnología y posibilidades de ser competitiva, a diferencia de Corea:

"El éxito de la industria automotriz Coreana para llegar a ser un productor mundial importante residió en la habilidad del gobierno para restringir la entrada a nuevos productores...No solo el gobierno de Taiwan sino también otros exportadores de carros como Brasil y México fueron menos exitosos para restringir esa entrada."(Wade: 1990: 311) 
Otros autores como Anglade y Fortin establecen las diferencias en los tipos de proteccionismo que aplicaron lo NICs y los países latinoamericanos. Ellos aseguran que Latinoamérica se caracterizó por una indiscriminada sobreprotección que impidió la competencia y estimuló la ineficiencia.

Ellos también señalan que entre los efectos negativos de la política de sustitución de importaciones esta la sobrevaluación del tipo de cambio para compensar los costos de las importaciones, resultando en obstáculos para exportar. (Anglade: 1987: 219).

\section{5.- ALTERNATIVAS A LA INVERSION EXTRANJERA Y FORMAS DE CONTROLARLA}

Los tres países bajo estudio Taiwan, Corea del Sur y México han ensayado en alguna época, diversas formas de control y alternativas a la inversión extranjera directa.

En el caso de Corea y Taiwan, las formas de control han sido principalmente en relación a limitar el acceso al país e inclusive han monitoreado la producción de las compañías extranjeras para controlar la economía más eficazmente.

México ha optado por caminos más formales pero de dudosa efectividad, al incluir restricciones legales a la inversión de extranjeros, como es el caso del artículo 28 constitucional.

La diferencia en ambos casos parece ser la profundidad de las medidas, la eficacia y la voluntad gubernamental por controlar la producción. Wade, afirma que los países asiáticos más destacados no han permitido que las compañías extranjeras controlen sus economías, por ejemplo:

"El acceso de firmas extranjeras al mercado doméstico ha sido controlado desde el principio. El temor a la dominación extranjera de sectores clave ha sido un elemento muy importante en el modo de pensar oficial, como en Japón y Corea del Sur"(Wade: 1990: 148)

- Corea del Sur, es quizás el país que mas ha levantado mecanismos de control a través de un cerrado monitoreo de la producción.

A las empresas se les giran instrucciones constantemente, para indicarles que tipo de productos deben crear y reportes muy precisos son enviados a las autoridades Coreanas.

-México nunca estableció un control tan estricto sobre la producción como lo hizo Corea. La estrategia seguida fue la creación de empresas públicas que pretendieron ser entre otras cosas instrumentos que salvaran a las 
empresas privadas en quiebra o ineficientes, comprando o participando en sus acciones (proteccionismo erróneo); pretendieron ser también detonadores de la producción y del empleo e incluso instrumentos de legitimación política, a través de las cuales se vendían productos subsidiados a la gente pobre. La inversión extranjera directa ingresaba a México en sectores de punta afianzando sus posiciones y dejando al gobierno intervenir con sus empresas públicas en áreas que en la gran mayoría de los casos eran poco significativas para la producción estratégica nacional.

- Taiwan por su parte, también creo empresas paraestatales que fueron sujetas a la competencia, con accesos restringidos al presupuesto del Estado, y en tal virtud alcanzaron altos niveles de eficiencia (Banco Mundial: 1991: 135).

\section{6.-EL PAPEL DE LA AGRICULTURA}

Aun cuando este ensayo se centra en el análisis del papel del Estado en la política de industrialización, es necesario comentar brevemente las diferentes estrategias que siguieron México, Taiwan y Corea en relación al tipo de propiedad jurídica con que se desarrollo el campo.

Taiwan y Corea buscaron hacer de la distribución de la tierra, un medio para redistribuir la riqueza al eliminar la propiedad de grandes extensiones. En Corea, el 69\% de los campesinos son poseedores de la tierra que ellos trabajan y en Taiwan, el $93 \%$ son pequeños propietarios con menos de tres hectáreas y no existieron propiedades mayores a las 10 hectáreas. Esto facilitó la estabilidad política y creo un sector agrícola poderoso para apoyar la industrialización. En México, se dio una combinación de regímenes jurídicos con ejidatarios y propietarios privados con extensiones medianas y grandes que desembocó en la ruina de los ejidos por la falta de apoyo financiero y técnico y por la transferencia de plusvalía del campo al sector industrial.

Considero que si bien el sector primario de la economía no es significativo en términos de participación en el total del PIB, si lo es en relación a las posibilidades de que funcione como un instrumento de legitimación política y de estabilidad. Sin duda, el caso de Chiapas avala esta afirmación. Los campesinos alzados en la región se lanzaron a una guerra suicida estimulados entre otras cosas por la insuficiente atención social que el gobierno y otros sectores sociales han perpetuado en esa zona. La distribución de la tierra esta muy lejos de ser justa y la concentración de la propiedad en pocas manos es muy evidente.

No es temerario afirmar que si la distribución de la tierra y el apoyo al campo en Chiapas y en otras partes del país, se hubiese dado en condiciones 
similares a las de Corea y Taiwan, los campesinos chiapanecos no tendrían motivo para iniciar una confrontación militar con el gobierno, pero en la situación en que viven actualmente es lógico que sean un caldo de cultivo idóneo para iniciar luchas tan desesperadas como suicidas. La violencia no se justifica pero las razones para llegar a ella están fincadas entre otras cosas en las enormes carencias económicas

\section{B)- ASPECTOS POLITICOS EL PAPEL DE NORTEAMERICA}

Una condición fundamental para evaluar la factibilidad de repetir el éxito de Taiwan y de Cocea es analizar el papel que Norteamérica jugó en ambos países.

Recordemos que el desarrollo de estos dos países empezó después de la segunda guerra mundial y en el contexto de la guerra fría. La seguridad nacional era la prioridad más importante, y en este contexto, Norteamérica no escatimaba su apoyo especial a los países considerados estratégicos para ganar posiciones geopolíticas importantes.

Taiwan y Corea del sur gozaron de este apoyo, por estar próximos a la "amenaza comunista" de China y Corea del Norte respectivamente.

La ayuda técnica y financiera norteamericana fue mayor para esos dos NICs de lo que lo fue para México y para Latinoamérica en general.

A propósito de la ayuda norteamericana a los NICs, Jenkins afirma:

"Hay poca duda de que en ausencia de la ayuda, el crecimiento en este período habría sido considerablemente mas bajo" (Jenkins: 1991: 39)

Jenkins asegura que un tercio de la inversión bruta y de las importaciones totales en Taiwan y más de dos tercios de ambas variables en Corea del Sur fueron financiadas con dicha asistencia.

Wade confirma la importancia de la ayuda norteamericana la cual empezó a fluir en 1950 en Taiwan con el estallamiento de la guerra de Corea:

"Con tanta ayuda quien no hubiera industrializado? Esto se ha dicho muchas veces.

Ciertamente la ayuda norteamericana fue muy importante" (Wade: 1990: 82)

Los gobiernos de Corea del Sur y Taiwan tomaron ventaja de la coyuntura. Sobra decir que esto permitió fortalecer la autonomía del Estado frente a los grupos de presión internos y las amenazas externas y facilitó las posibilidades del Estado de conducir la economía y de "gobernar el mercado" 


\section{LA DEMOCRACIA Y EL PAPEL DEL AUTORITARISMO 1.- DESARROLLO ECONÓMICO Y DEMOCRACIA}

Vamos a establecer la posible vinculación entre economía y democracia, porque consideramos que en el subdesarrollo la antidemocracia encuentra su caldo de cultivo, debido a la inestabilidad social, a la falta de cultura y a los problemas económicos entre otros factores. Quiero adelantar la conclusión de que el diferente nivel y tipo de crecimiento económico logrado por los tres países condicionó en mucho la calidad de sus democracias. El estado actual de la misma en los tres países es en cierta medida un reflejo de su nivel económico. Consideramos pues, que el crecimiento económico sustentable, facilita el mejoramiento de la democracia, tal y como lo afirma Kim Kyong-Dong:

"El desarrollo económico avanzado, produce gran seguridad económica y equidad, provee más educación generalizada, y consecuentemente ensancha la clase media. Esto a su vez genera distribución pluralista de recursos que es en sí misma una condición importante para la democracia" (Kyong: 1991:256)

Los tres países analizados recibieron acusaciones de haber sido antidemocráticos y autoritarios durante su proceso de industrialización.

Corea y Taiwan, sentaron las bases del desarrollo industrial bajo un esquema autoritario, que les resultó funcional al aplicar medidas económicas difíciles, que requerían el uso del poder del Estado tales como el proteccionismo, el monitoreo de la producción a los acuerdos entre el sector público y el privado, cuando estos perjudicaron a los segundos.

Al final, el proyecto de los NICs, condujo hacia la distribución con equidad, a diferencia de México, en donde uno de los principales obstáculos para el desarrollo democrático lo ha sido, la creciente concentración de la riqueza lo que mantiene ocupados a los ciudadanos al orientar sus esfuerzos en dirección de las demandas económicas y a postergar sus afanes de democracia política.

\section{2.- EL AUTORITARISMO}

Muchos autores coinciden en señalar que el autoritarismo ha sido un rasgo fundamental en el sistema político de los NICs, afirmación que diversos autores aplican a México. Sin embargo, han existido diferencias en la forma de hacer uso de este recurso político, para industrializar y para conducir políticamente sus países.

Gourevitch asegura que Taiwan y Corea han hecho un "uso constructivo" de una autoridad altamente centralizada. (Gourevitch: 1993: 1271). $\mathrm{El}$ autor clasifica a los dos países como naciones de pobres recursos con altas 
habilidades educativas, fuerte unidad étnica y con un sentido alerta para las amenazas externas. Ellos fueron capaces de crear un amplio margen de autonomía en relación a los grupos de interés y de la sociedad civil para manejar la economía y orientarla ya sea hacia la libre competencia o hacia el intervencionismo estatal según conviniera.

En relación a esta gran autonomía, Batley se refiere a la capacidad de los NICs para controlar los intereses de los terratenientes, los intereses financieros especulativos desvinculados de la producción o incluso para anular las presiones de las élites vinculadas a intereses extranjeros.

En México, aun cuando han prevalecido condiciones autoritarias, el gobierno no ha logrado en las últimas dos décadas autonomía suficiente para imponer decisiones en interés de la nación pero que afectan los intereses de los empresarios, de los banqueros o de los terratenientes. Baste citar el caso de Echeverría y López Portillo y sus sendos fracasos para ejecutar decisiones que afectaban a grupos poderosos.

Luis Echeverría nunca logró poner en marcha su idea de reforma fiscal para gravar el patrimonio de los que mas poseen; por otro lado, intentó poner bajo control a los medios de comunicación al acusarlos de dañar con sus mensajes las mentes del público receptor y por lo tanto sugerir el control del contenido de los programas de los medios. Por supuesto, no logró su cometido.

López Portillo trató de dejar en manos del Estado el control de los bancos al nacionalizarlos, pero la realidad de la debilidad del Estado frente a los intereses financieros y las presiones exteriores por iniciar el programa de "ajuste estructural" que recomendaba la menor participación del Estado en la economía terminaron por dar marcha atrás a la medida y por devolver los bancos casi de inmediato a manos de los particulares.

\subsection{EL AUTORITARISMO Y LA ELECCIÓN ESTRATEGICA}

Robert Wade, es uno de los autores que mas clara- mente ha expuesto las razones del éxito de los NICs y una de sus conclusiones más importantes es que la regulación del mercado (indudablemente un tipo de intervención del Estado en la economía), en ocasiones autoritariamente, ha jugado un papel fundamental en el desarrollo sustentable de los tigres asiáticos.

La regulación no ha sido ni con mucho indiscriminada (como lo fue la creación de paraestatales en México en los 70s.), sino mas bien muy cuidadosa y ha sido llamada "elección estratégica ", dicha elección condujo a buenos resultados en el crecimiento económico, distribución de la riqueza y, factibilidad de las políticas industrializadoras. 
Sobre la importancia de "gobernar el mercado", Wade afirma:

"Mi argumento es simplemente que los hechos derivados de gobernar el mercado son demasiado importantes para ignorarlos al explicar los resultados superiores de Taiwan, Corea y Japón"(Wade: 1990: 345)

El autoritarismo en los países asiáticos fue aplicado para regular el mercado, creando el Estado la autonomía necesaria para tomar decisiones que no favorecieran solo a los grupos de presión, sino al proyecto económico global.

El gobierno Mexicano orientó su tendencia autoritaria a hacer un uso patrimonial de los recursos dando concesiones y prebendas a los grupos leales al sistema y castigando a los disidentes. Las determinaciones entonces poco tenían que ver con estrategias económicas exitosas. Más bien, la estabilidad política fue el objetivo hacia donde las decisiones autoritarias enfilaron sus fuerzas.

El propio Wade, -compara el éxito en las medidas autoritarias tomadas por Taiwan y México:

"El autoritarismo y las políticas corporatistas en Taiwan dieron un poder firme al Estado. Pero cuales son las metas económicas hacia las cuales el poder del Estado debe ser dirigido? ... Es bueno recordar que México, difícilmente un modelo de éxito económico también tiene arreglos políticos autoritarios y corporativistas, pero dirigidos a diferentes metas" (Wade: 1990: 256)

Otro autor, Rhys Jenkins, en un artículo que compara a Latinoamérica con los tigres asiáticos asegura que el factor crucial en el éxito de Corea y Taiwan es el alto grado de autonomía del Estado y enfatiza la importancia que tuvo haber elegido el modelo correcto. En ese mismo artículo se critican las decisiones erróneas de Latinoamérica incluido México. (Jenkins: 1991: 51)

Tanto Taiwan como México se encuentran actual- mente en períodos de transición democrática, buscan- do sus respectivas formulas para apenas crear sistemas electorales democráticos y confiables. Las garantías de respeto al voto y de elecciones justas que parecerían cualidades obvias de los sistemas políticos de los países desarrollados son desafortunadamente todavía algo por alcanzar en México e incluso en algunos de los NICs.

Aun mas desafortunado es observar que los resultados del ejercicio autoritario del poder han sido muy distintos en los grupos de países de América Latina y de los tigres asiáticos, llevando a estos al crecimiento económico sustentable y dejando a los nuestros con modelos económicos agotados y fracasados y con expectativas poco confiables a futuro.

Es interesante citar la opinión de O'Donell sobre la democracia en Latinoamérica porque se ajusta mucho a las características de México Veamos:

El menciona, que nuestros sistemas políticos poseen una doble cualidad de ser "democracias delegativas", con "ciudadanos de baja intensidad". 
Con lo primero se refiere a las prácticas de toma de decisiones del Ejecutivo prácticamente sin consultar al pueblo o a sus representantes, debido a que parece haberle sido electoralmente delegado el derecho de hacer lo que el considere necesario y bueno para el país, sin consultas adicionales de ninguna especie.

Con lo segundo, ODomell explica una situación en donde el ciudadano puede esperar tener el voto garantizado e incluso ser este tomado en cuenta de manera justa. Ahí termina la ciudadanía. Sin embargo la "baja intensidad ciudadana" se caracteriza por existir una extrema disparidad en la distribución de la riqueza y un tratamiento inadecuado a los ciudadanos en asuntos donde interviene la policía y las cortes de justicia.

\section{C).- EDUCACIÓN Y TECNOLOGÍA}

Este es uno de los tópicos estratégicos que explican el origen profundo de las diferentes potencialidades económicas de los tres países. Los gobiernos de Taiwan y de Corea del Sur, han puesto una atención muy especial en avanzar hacia una política educativa muy firme que incorpore cada vez mas estudiantes en el nivel de la educación superior o "terciaria" (como la llaman muy comúnmente los autores anglo-sajones) con una orientación muy marcada hacia el avance de la ingeniería y de la química, ambas ramas muy necesarias para modernizar la planta productiva. Esto les permitió ser ahora competitivos en las áreas electrónica, química y automotriz, por citar solo algunas.

La ingeniería ha sido muy popular en Taiwan. A los ingenieros se les paga $20 \%$ más que a los egresados de las artes de la misma edad y $11 \%$ más que a los egresados de leyes. De aquí que para 1971, Taiwan tenía más ingenieros por cada mil personas empleadas en la industria manufacturera que muchos países con su mismo nivel de desarrollo con excepción de Singapur.

Corea del Sur, con una población de más del doble de Taiwan ha estado graduando últimamente tantos ingenieros como Taiwan en relación a su población

Esta excelente planeación educativa ha ayudado a Taiwan a asegurar el control nacional sobre las importaciones de tecnología y a adquirir gran maestría sobre esas tecnologías.

Durante las décadas de los 70s y los 80s los Taiwaneses constituían probablemente el grupo más grande de estudiantes extranjeros por país en los Estados Unidos. (Wade: 1990: 65) Este esfuerzo llevó a Taiwan a alcanzar el nivel de desarrollo educativo de algunos de los países de la Organización para la Cooperación y el Desarrollo Económico conocida como OCDE. (Richards: 
1993: 25). México por su parte no ha logrado desarrollar una política de educación superior consistente a lo largo de los años, como podemos verlo en la siguiente tabla (The OECD Observer: Oct/ Nov 1993: 25).

\section{PORCENTAJE DE GRUPOS DE EDAD INSCRITOS EN EDU- CACIÓN TERCIARIA (SUPERIOR)}

\begin{tabular}{lll}
\hline & 1965 & 1989 \\
\hline COREA DEL SUR & $6 \%$ & $38 \%$ \\
\hline TAIW AN & $7 \%$ & $33 \%$ \\
\hline MÉXICO & $4 \%$ & $15 \%$ \\
\hline
\end{tabular}

Como es fácil deducir de la tabla México ha sido negligente para invertir y estimular la educación superior, pagando las consecuencias en relación a dependencia tecnológica, bajo nivel educativo e incluso debilidad cívica de los ciudadanos.

\section{PLANES Y ESTRATEGIAS PARA EL DESARROLLO TECNOLÓGICO AUTÓNOMO DE LOS NICs}

Tomemos primero el caso de Corea, para analizar el importante papel que el Estado desempeñó al poner en práctica varios planes para crear una tecnología propia.

En el caso de la electrónica, ellos ejecutaron los planes llamados:

- Plan de la industria pesada y química en 1973,

- Plan de desarrollo de ocho años para la industria electrónica de 1974

Ambos planes consiguieron las siguientes metas:

- Crear instituciones de investigación públicas y privadas orientadas hacia una misión especifica.

- Expandir la capacitación avanzada en la electrónica. 313)

- Estimular las importaciones de tecnología vía licencias. (Wade: 1990:

Posterior a estos planes, Corea creo el Instituto de Tecnología Electrónica en 1976, estableciendo programas para enviar ingenieros y científicos al extranjero para extraer las experiencias en diversos institutos de investigación y firmas importantes, por ejemplo con la división de proyectos de desarrollo del "valle del silicón" en Estados Unidos. 
Taiwan por su parte, estableció la Organización de Investigación y Servicios en Electrónica que logró liderazgo y dominio en los semiconductores y tecnología de computadoras.

Por otro lado, Taiwan con frecuencia uso las empresas públicas para fortalecer nuevos campos en la industria automotriz y la biotecnología por ejemplo. (Wade: 1990: 321)

Es de destacarse el hecho de que nuestra proximidad geográfica con Estados Unidos no tiene que ser siempre una desventaja o infortunio, nuestras posibilidades de desarrollo tecnológico pudieron fortalecerse de haberse diseñado una política similar a la coreana para enviar ingenieros y científicos a capacitarse y a entregar su conocimiento en beneficio de México.

\section{BIBLIOGRAFÍA}

Anglade, Ch. and Fortin, C. (1987). "The role of the state in Latin Americas strategic options". Cepal review No. 31.

Batley, R. (1993) "The developmental State: The role of the state in the NICs" Handout for DAG 10.

Batley, R. (1993) "The role of the state in the newly industrialized countries". Handout for DAG 10.

Gourevitch, P. (1993) "Democracy and Economic Policy: Elective affinities and circumstantial conjunctures World Development, Vo121, No 8.

Harvey, N (1993) “Mexico Dilemmas of transition", London Institute of Latin America Studies.

Jenkins, R. (1991) "Learning from the gang: are there lessons for Latin America from East Asia? "Bulletin of Latin America Research Vol 10, No 1. Kyony-dong, Kim. (1991) "Sociocultural Developments in the Republic of Korea in: "Democracy and Development in East Asia", Washington DC Thomas W Robinson.

Luedde-Neurath "State Intervention and foreign direct investment in South Korea” Handout for DAG 10.

Naya, S. and Imada, P. (1990) "Development Strategies and Economic Performance of the Dynamic Asian Economies: Some

Comparison with Latin America", The Pacific Review, Vol 3 No 4.

Newsweek (1993) "Lifting the Imperial Veil", December 13.

O’Donnell, G. (1993) “On the state, democratization and some conceptual problems: A Latin America view with glances at some post communist countries" in World Development. Vol 21, No 8. 
Richards, A. (1993) "Korea, Taiwan and Thailand: Trade Liberalization and Economic Growth” OECD Observer, No 184, October / November 1993.

The Economist (1993) “Tale of two dragons", December 18.

Wade, R. (1990) "Governing the Market” New Jersey, Princeton University Press.

World Bank (1991) "Rethinking the State" World Development report Handout.

World Bank (1992) World Development Report. 